\title{
Social Entrepreneurship: Metaphysics of Entrepreneurship in Practice
}

\author{
A. A. Baryshev ${ }^{\mathrm{a}}$, G.A. Barysheva ${ }^{\mathrm{b} *}$ \\ * Corresponding author: Galina Barysheva. ganb@tpu.ru \\ ${ }^{a}$ Tomsk State University, 36 Lenin Ave., Tomsk, Russia, barishevnp@mail.ru \\ ${ }^{b}$ National Research Tomsk Polytechnic University, 30 Lenin Ave., Tomsk, Russia,ganb@tpu.ru
}

\begin{abstract}
http://dx.doi.org/10.15405/epsbs.2016.02.46

Contemporary capitalism is in such a condition that the recent objectives of enterprises' actions neither ensure that the owners of enterprises have any mode of justification nor guarantee legitimization by civil communities, which leads to destructive environmental and social implications. Making a profit at the expense of social and natural costs gets society in deadlock. Changing the vector of development depends on the interconnection of the social and the economic at the present-day life. In this paper we intend to propose a broad explanatory scheme of the evolution of the social throughout the known human history with regard to the present-day situation of blurring the mode of realization of social goals through achieving economic ones. This scheme is to pay great attention to the changes in social life fundamentals for the purpose of revealing the dialectics of the social and the economic within entrepreneurial activities in the phase-in development of knowledge society. The prototype of the new configuration of the social and the economic is the existing model of the social entrepreneurship. The model that harnesses the social and the economic in a new manner has appeared and has been tested in the non-turbulent niche of social entrepreneurship in the form of activity driven by humanistic values rather than merely economic ones. This makes it possible to create conditions, similar to laboratory ones, for earning a private profit by means of solving public problems.
\end{abstract}

(C) 2016 Published by Future Academy www.FutureAcademy.org.uk

Keywords: Social entrepreneurship; entrepreneurial action; rules of conservation of social substance; division of knowledge; humanification of network objects; entrepreneurial impact chains; social value.

\section{Introduction}

We used a wide range of conceptual means to substantiate our hypothesis. The study is based on the Weberian and contemporary concepts of social action. We addressed the concept of axial principle of social development by D. Bell to obtain historic modifications of conditions for the entrepreneurial action. Marxian conceptualization of sociality was used to define the inner structure of the entrepreneurial action. We employed the concept of justification by Boltanski and Thevenot. The Marxian theory of commodity fetishism and the Actor - Network Theory were examined to understand the objects created by the entrepreneurial action and their connection with the earned profit in different 
historic conditions. Comprehension of the entrepreneurial action required employment of the inventory of the Theory of Autopoiesis and the concept of self-organizing systems. Last but not least, we involved the contemporary theories of value related to the hybrid entangled objects able to generate self-substantiating action, which enabled us to consider the entrepreneurial action as an inner cognitive action of a hybrid network object. Then, we created the concept of the entrepreneurial action as simultaneously cognitive and instrumental one and used the concept of knowledge society as a comprehensive cover of the received construct.

The first finding lies in the fact that the entrepreneurial action is a universal category of human society that widely varies depending on the axial principle that a certain society is based on. With this in mind, an entrepreneurial action under traditional society is embedded in social relationship acting like natural forces. The second result is that social relationships under different axial principles have their own, distinct from the superficial mechanism of determining the social, social mode of functioning for the social. We have argued the design of the latter including, on the one hand, the substance forming a certain historic type of sociality and the rule of conservation of this substance that is specific to the corresponding type of sociality, on the other hand. There are different rules of conservation of natural factors, labour and knowledge as social-creative substances known in history. At that, being the basis of humans existence, they are basic values in the corresponding societies. The notion of values implies something that must be conserved by all means. So, we distinguish the following three historic rules of social substance conservation: deification, justification and humanification. Thirdly, we proposed that humanification is defined as a specific rule providing knowledge equivalence. This rule counterpoises the two incarnations of knowledge: personal knowledge and network knowledge. By means of humanification, humans and non-humans form complex network objects able for cognition. We define cognition as their capability of reconfiguring themselves in a response to outer impact, that is, to build cognitive chains of comprehension of outer world. In this context, profit in knowledge society is an integral feature of a chain of acts within a network object. This chain of acts forms a cohesive entrepreneurial action. Thus, an entrepreneurial action is simultaneously cognitive and practical and an entrepreneur acts by means of such chains of comprehension and construction of reality. Consequently, in knowledge society or under conditions of cognitive capitalism profit is a derivate of the creation of hybrid cognitive network objects that are able to solve social problems by creating social value.

\section{Three types of social objects and their fundamentals}

Social entrepreneurship is known as entrepreneurship in specific spheres of humans needs which are not usually met by conventional business. Previously, these needs were in purview of state, nonprofitable organizations or families and other forms of the so-called immediate communities realized though social care for the deprived. So, in conventional discourse social entrepreneurship is thought of as a kind of philanthropy of the stronger in favor of the weaker or direct reciprocity of the equals without short-term mutual equivalence. It is significant that now the distinction between business and social entrepreneurship is attenuated. Both phenomena are suffering from considerable permutations 
http://dx.doi.org/10.15405/epsbs.2016.02.46

eISSN: 2357-1330 / Corresponding Author: Galina Barysheva.Email: ganb@tpu.ru

Selection and peer-review under responsibility of the Organizing Committee of the conference

and require profound analysis that should clarify the interconnection of personal and impersonal factors for social and economic gains inherent to these forms of activity.

In this context, it is necessary to emphasize that classic entrepreneurship avoids any forms of immediate sociality. Its credo can be best expressed with the well-known phrase "nothing personal, just business". In fact, business tries to stand aside from any relations except relations with things and their owners. With this in mind, entrepreneurship manipulates things although they might be socially entangled like capital, commodities and money. Nevertheless, they still remain things but not humans. An immediate social action seems to be prohibited for entrepreneurs. Despite its social embeddedness (Granovetter, 1985) or social entanglement, an entrepreneurial action is not an immediate one. Social networks are rather means than the objective of an entrepreneur. It is general practice to define an entrepreneurial action as a purposeful rational action. Correspondingly, any efforts to endue this concept with relationship content turn it into a processual notion that contradicts the traditional point of view on purposeful rationality.

On the other hand, as long as the progress of hybrid things or consciously constructed entities united humans and non-humans (Latour, 2000) (id est internet communities or econocenosises of innovation activity) manipulating them like only-things becomes hazardous due to their inherent riskiness predetermined by intentions, preferences, expectations of humans they include (Latour, 2000). The principal entrepreneurs risks are to be involved in the relationship processes instead of being focused on the final goal and perform only purposeful partial acts or jobs, which are aggregated in the entire social action that appears to be in this context an economic or entrepreneurial one.

The questions to be answered are the following. Can the entrepreneurial action as a kind of social action, firstly, and a kind of economic action, secondly, be still interpreted as a purpose-oriented rational action? Or it has fully changed its nature and becomes a value-oriented-rational one? The third question is whether socialization of entrepreneurship existed initially, but it had the form of manipulations with social things on the reason of so-called commodity fetishism? If the latter is true, then we can treat the social embeddedness of an entrepreneurial action as the next evolutional move in the autonomization of social objects. Within this framework, the concept of commodity fetishism by K. Marx is a precursor of modern theories of social reality objects.

Our hypothesis is that there is historic change of the social from its being on the surface of things (like in the case of fetishism) to its penetration into things and their metamorphosis into wholly social substances. In the first case things are perceived as bearers of social relations or their reifications, while they themselves remain of natural and technical essence. Thus, there is separation of the world of social relations from the world of things. The obvious theoretical move is to acknowledge that the reason for this duality is the metamorphosis of labour into the axial principle of society when physical means of production coupled physical labour in order to obtain a physical product (Lash, 2007). The core of such society is labour that acts as physical force par excellence. So it produces physical things predominately. The gap between the material content and the social form of commodities becomes noticeable as far as they go up to their markets where released things-fetishes set relations between themselves behind producers' backs. Obviously, the shift of the axial principle from nature to labour does not lead to overcoming the naturalization of the social in practice. It cannot be overcome 
theoretically too. That is why Marxian concept of commodity fetishism looks so mystical allowing dual existence of things - physical and metaphysical, sensual and pretersensual.

The next step of evolution of social quality of man`s artifacts is the origination of the knowledge axial principle of society. Knowledge cannot be reduced to physics. It is a totally social phenomenon. Therefore, things made of knowledge are initially of both social and cognitive nature. Such objects of reality can exist only by means of persistent interactions between all their parts, which are in accordance with the latest conceptualizations, embodiments, generators and translators of knowledge. The most cryptic property of the cognitive (id est. social objects of reality) is not that they can resist and counteract to impacts of the environment but that they are able to adopt the impacts by changing their inner design. Developing Latour's metaphoric, social objects are not merely black boxes but they are predominantly cognitive ones. Their cognitive qualities are determined by the hybrid lay out of their content that equals humans to intellect-intensive non-humans. This equivalence is carried out by the dialectics of the live and as if live knowledge.

\subsection{The rules of conservation of social substance}

In contrast to the dialectics of live and dead, or reified labour, the dialectics of knowledge does not deal with dead things because both humans and non-humans transmit knowledge and change, develop and reproduce themselves in this process. Actually, the investigated equations are the reflexive processes of circulation of personalized and depersonalized kinds of knowledge. It is great simplification to understand the equivalence, or following the ANT vocabulary - symmetry of human and non-human actants literally, because the possibility of their network interactions is conditioned by the dialectical equivalence of "substances" incorporated in them. Predictably, the substance to be found is knowledge. Although both parts of the equation consist of knowledge, they are characterized with qualitative distinctions. Indeed, personal knowledge has no significance without intentional comprehension of knowledge that constitutes non-humans. Following Karl Marx, we can speak of a relative form of knowledge that turns into human value due to human`s involvement in existence and functioning of non-human agents. This involvement is not merely of speculative sense. It is of vital importance. That is why knowledge creates value, or otherwise, is a substance of value. On the other hand, knowledge comprehended by non-humans is not certain preterhuman knowledge because it has no existence without people able to scan and understand it. Correspondingly, knowledge exists in a relative form only. In contrast to the commodity value relativity, where the exclusive status of monetary commodity appears as a result of a long historic development, the Fundamental asymmetry of human and non-human parts of the equilibrium is primordial.

"The asymmetrical importance of human actors" is obvious at the earlier stages of creating new network objects. In this context, I. Tchalakov states that "key phenomena of passion, endurance, persistence and suffering inherent to human actors, ... are crucial for the success of innovations, especially of the radical ones - not only to cope with uncertainties in the process of design and making the new devices work, but also in breaking the old 'actors-worlds' and in overcoming the distrust, hostility and even resistance of the fellow communities" (Tchalakov, 2015). Non-human actants also 
http://dx.doi.org/10.15405/epsbs.2016.02.46

eISSN: 2357-1330 / Corresponding Author: Galina Barysheva.Email: ganb@tpu.ru

Selection and peer-review under responsibility of the Organizing Committee of the conference

have their own manifestations of their agency, that do not allow to refer them to multitude of dead human creations similar to those ones from the ages of classic capitalism, but the properties of genuine vitality that have just been spoken of belong to human beings only.

In this paper we confine ourselves to the indication of the fact that non-humans generated by knowledge are of absolutely another nature than social things produced by labour as a substance of sociality. This differentia specifica of post-industrial social matter formed by knowledge requires special fundamental studies which will be done as long as social-cognitive objects adequate to knowledge society such as 3-D printers (Harman, 2015), Powerpoint (Knolauch,2013), Internet of things (Santucci, 2010) and other will appear. So, we intend to concentrate on the changes in entrepreneurship determined by pervasion of new hybrid objects. Nevertheless, an address to mystic and metaphysic issues of commodity fetishism is inevitable.

The cornerstone issues on the essence of entrepreneurship under condition of emergence and proliferation of social-cognitive objects is the place of an entrepreneur in the space of hybrid network reality. Is an entrepreneur within a network or is he beyond it? This issue looks like the question on the relation of God to the nature. "Within?" or "Beyond?" - these are the crucial questions related to any cognitive type creators of reality including, undoubtedly, an entrepreneur. The Actor-Network Theory, as we can judge about it, places entrepreneurs within assembled networks but puts them beyond networks being constructed. We consider that this duality is a relic of the labour mode of production of social reality objects. Under this mode of social construction an entrepreneur as subject is opposed to outer object created by him according to the conventional scheme of the purpose-oriented action. This classical science approach to the entrepreneur treats him as the best piece of economic man in fact turns him into an economic superman or a super-economic man. This paradoxical thesis ought to be proved. For this purpose it is necessary to address the concepts of personification and reification, which are the core of the theory of commodity fetishism by Marx. Let us analyze the mentioned concepts closely.

The paradox of classic capitalism is that it is a world of universal reification where all of the economic agents are only personifications of certain social things and, thus, subjected to them. So, the movement and development of economy is determined by the logics of material conditions of production, but, on the other hand, functioning of the presented economic system is impossible without an economic actor who is able to unspell the next logical move in the run of this social machine and really realize (both words are used to outline the power of reification) the alienated logics. It is acknowledged that this economic actor is an entrepreneur. It is absolutely true with the only explicitation of that an entrepreneur is an economic subject, or agent. An entrepreneur, as he has been just presented, has to be out of an economic system. That is why the title of economic superman fits him best.

Under the conditions of industrial capitalism an entrepreneur turns out to be beyond the system of his own enterprise, firstly, and whole industrial capitalist system, secondly. The latter implies that he has to find decisions which are not available in the existing practice (in other words, they are beyond the circle of things). His external position also relates to the market, because his market behaviour cannot be explained on the basis of market incentives and categories only. As K. Polanyi showed, the 
delusion of economic determinism was inspired by the specific conditions of XIX century. This phenomenon considered as belief in determining the role of economic incentives is similar to Marx`s commodity fetishism, but in Polanyi `s version it is closer to its historic barrier and therefore is more burdened by its own oppositions. The opposition to domination of economic incentives is prevalence of social ones such as "social good-will, social status, social assets", therefore "man`s economy is, as a rule, submerged in his social relations. The shift from this to society, which was, on the contrary, submerged in the economic system, was absolutely novel development" (Polanyi, 1947).

This novelty owes its origin to liberation of labour from ties of nature, but along with this emancipation the primordial unity of people was lost. The victory of the labour as axial principle of society turns into humiliation of labourer and now "instead of the economic system being embedded in social relationships, these relationships were embedded in the economic system" (Polanyi, 1947). Prima facie the social was subjected to the economic. But it seems to be so at the first and conventional sight only. Virtually, it turned out to be that the economic doesn't subordinate the social, but the latter radically changed the mode of determination of economic processes as compared to the previous mode of determination. The visible result of the metamorphose is the appearance of individual man who firstly gained an ability to create his social world independently, no matter that his independence had very close limits at the early stage of evolution of labour society. Nevertheless, it is labour that creates man. Today, the causes of this transformation are not quite known, but they are known to create the visibility of the priority of economic incentives and economic values. It is necessary to understand the mode of substitution social valuables with economic ones and historical interconnectedness of the two types of axiological phenomena for the purpose of explaining the above marked super-economic properties of an entrepreneur's behavior as well behavior of other economic agents. This objective differs from the intention of Boltanski, Thévenot and their followers to describe various modes of man`s involvement in capitalist relationship grounding on the concept of justification as means of providing social balance (Boltanski, Laurent Thévenot, 2006). They elaborate an image of modern cognitive capitalism in the terms of equivalence to be justified (Boltanski, Chiapello, 2007). Another solution is impossible if capitalism is viewed on as a real subject of research. We consider that the observed society comprehends different islands and continents of relationships which do not suggest the indicated mechanism of maintenance of social balance. We believe that there are other means of establishing equivalence except justification both in humans history and in the present day society. Hereinafter, we will show the significance of the issues to be addressed for comprehending the peculiarities of contemporary entrepreneurship and the congruence of the economic value produced by business and the social value delivered by social entrepreneurship in post-labour society.

Presently, it is clear that pre-labour society did not know the division of humans ' life into social and economic components. The essential parts of human existence were sacred actions and temporal matters rather than social and economic activities. According to Karl Polanyi (1947), it implied that all actions were submerged in social relationship. That submergence was the predetermined by predominance of natural sources of the social (id est gender, age, clanship or consanguinity and territoriality). Whereas the natural acts prima facie like the social, we face a situation that is similar to economic determinism. In traditional societies it is very convenient to explain everything through 
http://dx.doi.org/10.15405/epsbs.2016.02.46

eISSN: 2357-1330 / Corresponding Author: Galina Barysheva.Email: ganb@tpu.ru

Selection and peer-review under responsibility of the Organizing Committee of the conference

action of natural things and forces but the natural cannot act in a human way, that is to say, consciously and voluntarily. Consequently, we are sentenced to seeking for intermediations between the two sides of reality and find them in the world of meanings, in the sphere of the sacred or grosso modo - in mental substances. In this regard, some investigators conclude that traditional societies are more knowledge societies than nature-based ones. Indeed, Gernot Bohm and Nico Stehr describe "ancient Israel as society structured by its religious law like Tora knowledge or ancient Egypt, in which religious, astronomical and agrarian knowledge served as the organizational principle and as the basis of authority" (Bohm, Stehr,1986). This implies that any type of determinism passes by the substantial issues of man`s reality that makes impossible to understand flows of actions, changes of their directions and the variety of real living forms of sociality under the same natural or technical prerequisites.

In order to reveal the essence of the stated points, one is to shift the research focus from natural or technical circumstances to processes of socialization of humans and their actions. Such approach brings us to the forefront of intrinsic substantiation of processes instead of extrinsic ones such as nature and machinery. The modes of this substantiation on the assumption of the labour criterion of periodization of history are deification, justification and humanification for pre-labour, labour and post-labour societies, respectively. For example, the first stage of human socialization implies socialization of man`s nature as a whole along with the accessible outer world through awareness of their resemblance to God. This resemblance is a specific mode of social equivalence of things and actions and thus it requires a gigantic installation and institutions of commeasuring their meanings. Due to its sanctification and deification the natural starts to play the role of the social with humans tremendous physical and mental exertion. So, creation and maintenance of the social is the main energy-intensive matter in traditional societies.

Then, socialization enacts labour as more delicate and obedient material for human`s selfaffirmation in the world but at the same time making his existence dissociated. As in the case of deification, the intrinsic distinctions of labour (id est live and dead labour, individual and cooperated labour, independent and hired, concrete and abstract, productive and non- productive labour) are not able to create real society without intermedia connected with the mental sphere of meanings, knowledge and beliefs. Therefore, by means of labour an individual man can distinguish himself from primary entity. He cannot anymore follow merely common convictions. Instead of common meanings provided by attribution of the social to the sacred, an individual needs personal justification of his actions, that is to say, assignment of personal meaning to them. Thus, sanctification of social action substitutes for its justification.

Although juxtaposition of meanings of humans action starts to occur on the market of produced goods post factum as their price fixing, the main condition of this must be met ante factum. Since man's action to be of social meaning requires alienation of ability for labour, it must be justified before. So, the real mode of equivalence in labour society acts through justification. Justification is an operation of equalization of physical sufferings delivered by labour to personal satisfaction from goods and services to be got in return. It also can be called speculation or calculation of the balance benefits and losses in their specific forms in every spheres of life named by originators of economic sociology of conventions as polities or cities (Boltanski, Laurent Thévenot, 2006). Obviously, an agent of labour 
or a human suffering from pains and hardships and an actor satisfying his requirements differ a lot despite the fact they are still embodied in the same person. Boltanski and Chiappello claim, “...the spirit of capitalism assumes reference to two different logical levels. The first contains an agent capable of actions conducive to profit creation, whereas the second contains an agent equipped with a greater degree of reflexivity, who judges the actions of the first in the name of universal principles." (Boltanski, Chiapello, 2007). Without this duality provided by actors' competences, it would be impossible for them "to understand the critiques directed at capitalism in so far as it is profit-orientated, or to construct justifications to foil such critiques" (Boltanski, Chiapello, 2007). Moreover, it enables capitalism to adopt its enemies' critiques as its own intrinsic instance of self-consciousness. Thus, without being justificated by human' mental and reflexive capability, capitalism is fundamentally impossible because material motives themselves are "insufficient to induce commitment and stimulate enthusiasm for the task, the wage constituting at most a motive for staying in a job, not for getting involved in it" (Boltanski 1, Chiapello, 2007).

The observed critical ability is of importance not only to the justificate buying and selling man power and making a profit, but also to ensure the metamorphosis of knowledge from an instrument of labour and its justification into social matter that forms all the objects of social reality. As opposed to the formal intellect that constitutes part of man power, practical intellect, creative intellect, social intellect, emotional intelligence as forms of subjectivity are gradually becoming more and more autonomous modes of constructing reality inasmuch as they have to solve increasingly sophisticated and complex issues of justification. The latter circumstance has two causes. The first one is connected with that labour being the independent substance of sociality developed its productivity that can weaken the threat of hungry as a labour incentive. The second cause is that maintenance of economic incentives requires more personal intellect to justify them and create more favourable living and working conditions to relieve the hardships of hire status of labour. Apparently, the above-mentioned second level capacities (id est personality or subjectivity of humans) turn out to be involved in business practice. In fact, this implies socialization of humans` knowledge. Since knowledge exists while being addressed to and shared with others, it is obliged to bear communicative, cognitive, creative, sensitive and emotional properties.

The question that has to be answered in this regard is the following. How can unalienated properties, which are utterly personal and, from the viewpoint of philosophical language, immanent to human`s self, constituting his superego, be socialized or transform into the agents of socialization. The introduction of personal properties and relationship in the discourse of social matter or substance seems to be a return to the interactionist approach to the social that cannot, as Latour has proved, explain the endurance of society and occurrence of its past and future (Latour,1996). At first glance, the facts of the present-day reality prove the correctness of the interpersonal mechanism of social construction. We consider that the reason is that many categories referred to personality such as credence, self-devotion, belief, and so on are observed not in the context of knowledge as a constructive matter of society but rather in the context of abstract humanity requiring the phenomena of human weakness. The background of undervaluation of personal aspects of knowledge is reduction of its content to information. We agree with those authors, who place information into technical categories while 
http://dx.doi.org/10.15405/epsbs.2016.02.46

eISSN: 2357-1330 / Corresponding Author: Galina Barysheva.Email: ganb@tpu.ru

Selection and peer-review under responsibility of the Organizing Committee of the conference

considering knowledge as a social one. Consequently, the concept of information society is based on technological determinism, whereas the notion of knowledge society "highlights the role of the human actor" (Knolauch, 2013). So, the task considering knowledge as substance of sociality is reduced to defining mode of mutual transition of the personal and the social.

While pursuing this objective, we have to notice that maturing of knowledge as material and a form of social construction happens according to the logics similar to the one of the development of labour social substance. Knowledge will have to develop its socialization both as matter and a form of social ties through its division. In the similar context H. Knoblauch notes that "it is possible to assert that the dynamics of the production of knowledge are subject to the same forces which propel the production of commodities: the increased differentiation and independence of production corresponds to the growth and differentiation of science" (Knolauch, 2013). Thus, we can consider division of knowledge as the starting point of the social theory of knowledge society.

The first division of knowledge into critical intellect and formal intellect is done within labour society. At the next stage critical intellect is split into practical intellect that allows a person to build justifications of alienation and involve himself in the changing market and capitalist reality according to circumstances and cognitive intellect that can generate contexts and concepts for others. One more part of knowledge definition presents social and emotional intellect, which reflects a new level in progress of socially meaningful qualities of knowledge as a base of social reality. Now these categories, which appeared in psychological discourse before, are successfully on-stream in popular literature on business and personal development. Nevertheless, being of great social meaning these categories themselves can generate a flow of speculations on the nearness of knowledge society. In theoretical context, these categories of intellect cannot form a social matter without being rooted in the ground of fundamental ones that initially are connected by the process of carrying out the main equivalence of the society under investigation.

As it was outlined before, the fundamental distinction of new society is the opposition of personal knowledge and objectified knowledge. Since knowledge has a network form of objectivation, objectified knowledge can be defined as network knowledge. The accomplished transformation of knowledge into the substance of social reality occurs at that time when the process of creation of objects of reality becomes cognitive. We hesitate to define this state positively because cognitive environment is being created now. But we can already provide a negative definition: knowledge becomes a socio-creative substance when cognition and action become impossible without being connected to general intellect.

\subsection{Towards the general theory of value and entrepreneurial action relevant to knowledge society}

The elaboration of the category of general intellect is based on Marxian views and whilst carrying out within radical-humanist paradigm (Morgan,1980) par excellence (Virno, 2004; Gortz 2003, Hardt \& Negri, 2000) But one can perceive it physically imagining oneself within a computer. The main attribute of cognition is ability to perceive outward things. So, the evolution looks like the following 
historic range of capabilities of artificial objects: "in the nineteenth century, machines learned to do; in the twentieth century, they learned to think; and in the twenty-first century, they are learning to perceive - they actually sense and respond." (Santucci, 2010). Owing to the Internet of Things and other technologies allowing to pervade increasingly humans` physical presence in the world, humans will perceive outward things and each other as if immediately, while outward things and persons will perceive them too.

Under such conditions we ought to differentiate the content and mode or form of transition of the personal in the social and vice versa. The content is obviously reduced to what we can mark as comprehensive reciprocity. Comprehensive reciprocity implies exchange of knowledge and meanings in order to create surplus knowledge. A reliable scheme of such knowledge-creation process is proposed by the founders of knowledge management I. Nonaka (1991). There are socialization, externalization, combination and interiorization (SECI) constructive parts in the concept of the company creating knowledge. Although this model is based on the most important exchange process between the external and the internal in an intellectual company, it cannot be applied to the fundamental social equivalence in knowledge society, whereas it treats men as the only agents of cognitive process and is limited to the size of a corporation.

The paradox of knowledge society is that people, on the one hand, are included in and are used by the entities possessing their own cognitive ability and, on the other hand, people have their separate subjectivity that uses their fixed cognitive objects for cognition and action. We consider this phenomenon as a shared cognitive-constructive net. Yet the key problem remains unsolved. The question is why all this complexity should exist. The best available way of comprehending the sense of the mode of comprehensive reciprocity is to address a proper metaphor that can assuage the impossibility of acceptance of symbiotic life of the live and "as if live" entities. This metaphor can make it possible to experience not only the utilitarian sensation of cognitive objects but also to experience what is conventionally connected with the principle of common humanity (Boltanski, Laurent Thévenot, 2006). In the light of the proposed metaphor knowledge exchange and the sense of its inner equivalence can be described as humanification of the world. So, we have a range of historic sensemaking procedures: deification, justification and humanification. Humanification means transformation of the world into a body of humans ' think and action, while human becomes the cause of development of the world he is responsible for.

Now the substance of social life and the nature of values changes radically. Social value is completely rehabilitated so that the economic is submerged in the social again. But it attains new mode of realization. Actions are appreciated now according to their contribution to the humanification of their results, which is achieved by granting them part of personal intellect. These human brainchildren, being network objectivations of humans' personal intellect, behave as if they were living rational beings but, in fact they are outer organs of man`s cognition and actions. This contradictory situation changes the notion of object. The object now is a net configuration of cognitive flows generated in the network of general intellect as response on a certain outer or inner impact or, that is to say, an object is an objectified solution in provoked by the impact within shared among humans and non-humans that is the nearest form of general intellect. 
http://dx.doi.org/10.15405/epsbs.2016.02.46

eISSN: 2357-1330 / Corresponding Author: Galina Barysheva.Email: ganb@tpu.ru

Selection and peer-review under responsibility of the Organizing Committee of the conference

But what is with the notion of value under this condition? Generally, a value is what can provide adequate and as full as possible comprehension of some event. In knowledge society the comprehension is a reconfiguration of an inner structure of something that occurs to be an object of an impact. So, an object is not pre-given, but it is the place pointed by impact and where a responsible configuration ought to appear. The concepts of cognition or comprehension as reconfiguration of entity in response to an impact are borrowed from the theory of autopoiesis by Maturana \& Varela (2000). The notion of value based on autopoiesis enables us to find an approach to describe the entrepreneurial action as humificated (unlike sanctificated or justificated as in previous ages) with immediate social value or, that is the same, meaning of it. The prototypes of such explanation are now elaborated postindustrial theories of value.

One of the first attempts to grasp the core of the contemporary meaning of an economic or entrepreneurial action is the conception of the co-creation of unique value with customers by C.K. Prahalad and V. Ramaswami (2004). They argue that value earned by modern high-tech companies as distinguished from firms of classic capitalism originates from interaction with customers on the principles of dialogue, access, risk assessment, and transparency (DART). Virtually, the authors regard the process of intellectual production as the process that, on the one hand, creates communities interested in its output and, on the other, is persistently improved and reconfigured under the influence of knowledge generated by the communities. As gurus of management C.K. Prahalad and V. Ramaswami consider their DART-model not only an explanatory scheme, but mainly as a managerial and entrepreneurial instrument allowing to apply the blocks of DART inventively in different sets. As a whole, this conception focused on practical issue of business and treating communities in technicist way as communities in computer networks primarily does not claim the role of a comprehensive theory of value. So, we are convinced that a general theory of value must be a theory of social value. This way, revealed earlier for social entrepreneurship (Brooks, 2008), now is a comprehensive one.

Another theory of value presenting more social approach is a conception of shared value by Porter \& Kramer (2011). They pay more attention to social interactions which create broad platforms capable of autopoiesis. This conception turns out to be an adequate one for impact projecting and impact financing, that is, for a very big business mainly that creates the value of association before creating market value of its results.

Curiously enough, this theory appropriate for big integrated business providing reconfiguration of the interconnection of the social and the economic is starting to play the role of a reliable methodological platform for social entrepreneurship. The cause of the resemblance of contemporary methodological approaches regarding industrial business social entrepreneurship lies in the fact that social entrepreneurship is a germinative form of entrepreneurial activity in knowledge society.

\section{Conclusion}

We would like to highlight the fact that our problematization of the entrepreneurial action under post-industrial reality impels us to shift the research focus towards the interconnection of the social and the economic in various historic periods. In this historical context, the social should be considered as self-substationating on its own (id est social) base. This social base is a substance of certain sociality. 
The change of such substance turns out to be the change of the type of sociality. Under these premises, the entrepreneurial action is a kind of social action aimed at the change and escalation of social substance complexity.

The essence of the problem is the issue of the status of the entrepreneurial action in transition to knowledge society. We support the hypothesis that social entrepreneurship is the prototype of entrepreneurial actions under knowledge society.

The justification of the hypothesis is based on the concept of social action and its different presentations under various types of sociality described in the theory of commodity fetishism by $\mathrm{K}$. Marx, the Actor-Network Theory and the theory of autopoiesis. Since the meanings of the entrepreneurial action cannot be described in economic terms, the issue requires addressing modern conceptualization of value and they are also engaged in the discourse.

In this paper we showed that the specifics of the entrepreneurial action are connected with how the social is connected with things in various periods of history. In the ancient ages the distinction between the natural and the social was not comprehended due to the special mechanism of sanctification of humans' environment. Later on, human products became bearers of the social whereas themselves they remained of natural or technical nature. This state originated the phenomenon of commodity fetishism. Thus, there is a separation of the world of social relations from the world of things. An entrepreneurial action under these conditions is mainly an economic one aimed at production of things which, as we have said, have an extrinsic superficial social form. The cause of this is the existence of labour as a social substance.

According to our explanatory scheme in all historic periods all things must be considered as coagulates of a certain social substance that is predominant there. Only under this point of view social actions might be perceived in proper logics of the society where they are committing. But it is not sufficient for their meanings understanding. The latter requires two conditions. Firstly, an action must be necessary for its performer. Secondly, an action must be directed towards others within society reproduced by means of a similar action of its other members. These two conditions imply that laws of conservation have universal meaning and also relate to social reality. Social matter discontinues to be perceived metaphorically now because the social cannot appear or disappear deliberately.

This approach suggests not only acknowledgement of the existence of social substance but requires singling out a specific mode of procurement of conservation of a certain historic substance. It is of great significance in our discourse that this mode (along with conservation of social substance) also provides involvement of actors in social action. So, the social balance of activities and actors' involvement in those activities are the same process of conservation of social substance. Its main function is prohibition of the actions, which are destructive for society. We significate different historic types of this mode as rules of conservation for a certain historic substance of sociality.

We differentiate three rules of social substance conservation. Ancient societies maintained and endowed their inner balance and endowed their members' actions with meaning through the deification of their world. Scientific schemata of modernity treat it as fetishization of natural and artificial objects and physical qualities of people. Commodity production generates a new rule of maintenance of the balance of its inherent labour substance of relationship. Owing to the school of conventions, it is 
known as justification that underlies each act of exchange and each social action in society based on labour. The general base of justification is an equivalence of live labour and reified one. The entrepreneurial action is justified under the conditions where it is merely an economic action.

The situation changes critically when knowledge starts to play the role of social substance. The mechanism of justification ceases to procure the inner equivalence of knowledge social substance. Its conservation and, correspondingly, actor's involvement is fulfilled by means of equalization of personal knowledge to network knowledge. It implies that human intellect is partially carried outside into the sphere of social general intellect and it does not need justification. Another problem arises when humans`environment is presented by not only artifacts but mainly by brainchildren. Since, humans are always within some network hybrid object (that is a continuation of his intellect) each human action is executed as cognitive one. As the organs of cognition are allocated in network space, this process implies reconfiguration of the space simultaneously. The entrepreneurial action gets social meaning or value but only when it destructs this environment and adapts its order to solve inner and outer problems. We call this rule of conservation of knowledge substance "humanification of social environment". Simultaneously, it determines the meaning and social value of each kind of action including the entrepreneurial one.

Thus, the entrepreneurial action is subject to creation of social value. The present-day model of business generating social value directly can be regarded social entrepreneurship, which enables us to consider the latter the reliable prototype of entrepreneurship under knowledge society.

\section{Acknowledgement}

This work was performed by the authors in collaboration with Tomsk Polytechnic University within the project in Evaluation and enhancement of social, economic and emotional wellbeing of older adults under the Agreement No.14.Z50.31.0029 (19th of March, 2014).

\section{References}

Granovetter M. (1985). Economic Action and Social Structure: The Problem of Embeddedness . American Journa l of Sociology,91( 3), 481-510.

Latour B. (2000). When things strike back: a possible contribution of 'science studies' to the social sciences .British Journal of Sociology,51(1), 107-123.

Lash S. (2007). Capitalism and Metaphysics, Theory. Culture \& Society, 24(5),1-26.

Tchalakov I. (2015). Guest editorial preface. Special Issue on New Space Entrepreneurship and Additive Manufacturing (3DPrinting) as Challenges to Actor-Network Theory. International Journal of Actor-Network Theory and Technological Innovation,7(1), iv- ix.

Harman H. (2015). 3D Printing and Actor-Network Theory Theory. International Journal of Actor-Network Theory and Technological Innovation,7(1),1-9.

Knolauch H. (2013). Powerpoint Communication, and the Knowledge Society. New York: Cambridge University Press, 252 .

Santucci G.( 2010). The Internet of Things: Between the Revolution of the Internet and the Metamorphosis of Objects. Vision and Challenges for Realising the Internet of Things / Edited by H. Sundmaeker, P. Guillemin, P. Friess, S. Woelfflé. - Luxembourg: Publications Office of the European Union, 11-24.

Polanyi K. (1947). Our Obsolete Market Mentality: “Civilization Must Find a New Thought Pattern” .Commentary, 3(2), $109-118$.

Boltanski L., Laurent Thévenot L.( 2006). On Justification: Economies of Worth. Princeton and Oxford: Princeton University Press, 400 .

Boltanski 1., Chiapello E.( 2007). The new spirit of capitalism.Translated by G. Elliott. - London and New York, 601. 
Bohm G., Stehr N. (1986). The growing impact of scientific knowledge on social relations. The Knowledge Society, Sociology of Science Yearbook / Edited by G. Bohm, Stehr N ., 10, 7-29.

Latour B. (1996). On interobjectivity. Mind, Culture, and Activity,3(4), 228-245.

Morgan G. (1980). Paradigms, metaphors and puzzle solving in organization theory. Administrative Science Quarterly, 25( 4),605-622.

Virno P. A.(2004) Grammar of the Multitude: For an Analysis of Contemporary Forms of Life. Trans. I. Bertoletti, J.Cascaito and A. Casson. N.Y.: Semiotext[e], 120.

Gorz A. (2003) L'immatériel - Connaissance, valeur et capital, Paris, Galilée, 298.

Hardt M, Negri A.( 2000)Empire. Cambridge, Massachusets .London, England: Harvard University Press, 478 .

Nonaca I.( 1991)The Knowledge-creating company. Harvard Business Review, 105.

Maturana H.R., Varela F.J.(1980) Autoiesis and cognition: The realization of the living. Dordrecht: Reidel.,143.

Prahalad C. K., Ramaswamy V. (2004)The Future of Competition: Co-cCreating Unique Value with Customers. Boston, MA: Harvard Business School Press ,257+xiii p.

Brooks A.C. (2008) Social entrepreneurship: modern approaches to social value creation. Upper Saddle River. N.J.: Prentice-Hall.

Porter, M., Kramer M.( 2011) The Big Idea: Creating Shared Value; How to reinvent capitalism—and unleash a wave of innovation and growth , Harvard Business Review 89.-Issue 1/2.- P. 62-77. 